\title{
Common Problems Related to Podiatry
}

\author{
LK Shankhdhar ${ }^{1 *}$, Kshitij Shankhdhar ${ }^{2}$, Smita Shankhdhar ${ }^{3}$ \\ ${ }^{1}$ Chief Diabetologist- LK Diabetes Centre, Lucknow, India. \\ ${ }^{2}$ Diabetologist and Podiatrist- LK Diabetes Centre, Lucknow, India. \\ ${ }^{3}$ Junior Diabetologist- LK Diabetes Centre, Lucknow, India.
}

*Corresponding Author: LK Shankhdhar, Chief Diabetologist- LK Diabetes Centre, Lucknow, India.

Received Date: 28 October 2021 | Accepted Date: 10 December 2021 | Published Date: 03 January 2022

Citation: LK Shankhdhar, K Shankhdhar, S Shankhdhar (2022). Common Problems Related to Podiatry. Endocrinology and Disorders. 6(1): DOI:10.31579/2640-1045/108

Copyright: (c) 2022 LK Shankhdhar, This is an open-access article distributed under the terms of the Creative Commons Attribution License, which permits unrestricted use, distribution, and reproduction in any medium, provided the original author and source are credited.

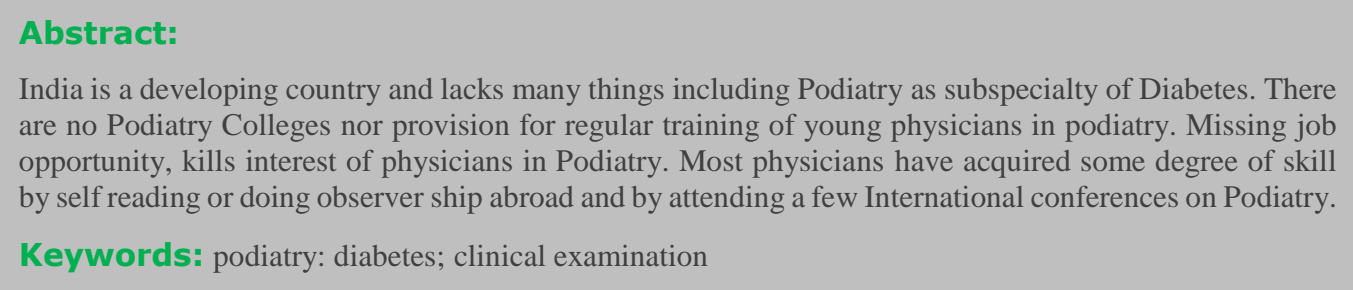

\section{Introduction:}

India is a developing country and lacks many things including Podiatry as subspecialty of Diabetes. There are no Podiatry Colleges nor provision for regular training of young physicians in podiatry. Missing job opportunity, kills interest of physicians in Podiatry. Most physicians have acquired some degree of skill by self reading or doing observer ship abroad and by attending a few International conferences on Podiatry.

Under the circumstances, level of knowledge of an average patient can be expected to be poor. This article aims at emphasizing common errors by Indian patients pertaining to the field of podiatry. We are providing only qualitative account and have not gathered data for quantitative expression.

\section{General Errors:}

Neither physicians ask nor patients insist on regular feet examination during their visit to physicians. Physicians ask to put off shoes only when some patient complains of some major foot problem such as a wound or an abscess.

Even during clinical examination, very few physicians have magnifying lenses to examine foot problems closely.

Provision for podiatric investigations such as monofilament, Biothesiometer, Audio Doppler, foot mats and thermotip are available with only few physicinas in big towns. Ofcourse tuning fork is available with most but they use it rarely.
Interestingly fewer government hospitals have provision for foot care compared to private clinics.

Therapeutic measures such as insoles, custom shoes, total contact casts etc are not available under one roof. Most measures are available with orthopedicians either at their clinic or they call the provider by phoning.

Even for surgical care for minor and major amputations, patient is referred to a general surgeon or orthopedic surgeon.

\section{Shoe Related Errors:}

General rule is that shoe is discarded only when a cobbler refuses to repair. Thus shoes last lifelong.

Many patients get calluses, corns and even ulcers due to ill-fitting shoe or poorly repaired shoe.

No shoe shop has a horizontal scale for measuring foot size, instead avertical one is routinely used.

No patient has information that shoes should be purchased in the evening. So most patients purchase an ill-fitting shoe.

In many cases insole is torn or missing totally.

Even holes can be found in insoles which might result into ulceration.

Fewer patients use shoes; most have poor sandles or chappals. 
One variety is very popular among economically weaker persons. It is a chappal made of crude tyre. It is very tough and not fit for use even when new.

\section{Barefoot Walking:}

Bare foot walking is common in still poorer individuals. These individuals have very tough plantar soles with many cracks.

Taenia pedis is frequent with itchy skin and cracks between toes, especially between $4^{\text {th }}$ and $5^{\text {th }}$ toes, due to barefoot walking coupled with frequent wetting of the feet.

Mycotic infections of nails (Taenia unguum) is frequent with hoof like nails,poorly trimmed or not trimmed at all for years. Many a times bathroom surgeries are performed on these nails with attended hazards.

Dermatitis is frequent mostly on ankle regions.

Neurodermatitis affecting lower parts of legs symmetrically is very frequent.

Many experimental therapies on patches of dermatitis by quacks make jobof informed physicians more difficult. One patient came to me with a big ulcer over a dermatitis patch after applying acid as per advice of a quack.

Many indigenous applications are applied ranging from diesel and cow dung to ash.

Fulminant infections follow poor therapies.

\section{Dressing relates:}

Dressing is done at surprising intervals; mostly when it is too stinking and dirty. To increase interval, patients often wrap a polythene around the dressings and change polythene only.

Physicians charge heavily for dressing since plight of dressings and wound is very bad.

\section{Socks related:}

Many individuals don't wear any socks, as they are not required withchappals and sandals.

No special socks are used. Socks of synthetic material are frequently usedsince cotton socks are relatively costlier.

Torn socks with holes or poorly repaired socks are used for pretty longbefore being discarded.

Frequent washing is not seen so socks smell badly.

\section{Tests related:}

Annual foot checkup is not undertaken routinely due to financial constraints.

Patients get foot checkup tests only when medical problem is far advanced.

\section{Interference with Surgical Intervention:}

Patients do not agree to minor surgeries such as corn and callus removal, which are flood gates for ulceration and potential risk for amputation.

Even when amputation is imperative, patients don't agree for it and wastetime and money for no avail.

\section{Conflict of Interest:}

All the authors declare that they have no conflict of Interest.

\section{Acknowledgement:}

We acknowledge this article to Late Dr. Uma Shankhdhar who became victim of Covid Pneumonia in May, 2021. She had contributed immensely in preparing the draft of this article before her death.

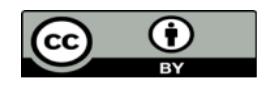

This work is licensed under Creative Commons Attribution 4.0 License

To Submit Your Article Click Here:

Submit Manuscript
DOI: $10.31579 / 2640-1045 / 108$
Ready to submit your research? Choose Auctores and benefit from:

$>$ fast, convenient online submission

$>$ rigorous peer review by experienced research in your field

$>$ rapid publication on acceptance

$>$ authors retain copyrights

$>$ unique DOI for all articles

$>$ immediate, unrestricted online access

At Auctores, research is always in progress.

Learn more https://auctoresonline.org/journals/endocrinology-and-disorders 